\title{
Big Five Personality and Employee Adaptability: A Study on Multigenerational Workforce in Banking Industry
}

\author{
J.K.D. Madusika ${ }^{1}$ \& A.K.D.N. Dilshani ${ }^{2}$ \\ 1,2 Department of Business Management \\ Faculty of Business Studies \& Finance \\ Wayamba University of Sri Lanka \\ SRI LANKA \\ dimithrijayakody@gmail.com ${ }^{1}$,dilshani@wyb.ac.lk²
}

\begin{abstract}
Resilient banking sector is crucial for the development of economy. Developing adaptive and agile employees to navigate changes in technology, job roles, and job location so forth are the contemporary challenges faced by banking sector. Increasing employee adaptability is a highly concerned subject due to the personality differences of different generational workforce. The impact of big five personality traits on employee adaptability is slackly addressed phenomenon. Thus, study was done with the intention of investigating how big five personality traits impact on employee adaptability among targeted multiple generations; generation $\mathrm{X}, \mathrm{Y}$ and $\mathrm{Z}$. A deductive, cross sectional investigation was carried out. Conceptual model was developed through critical review of literature comprised neuroticism, extraversion, openness, agreeableness and conscientiousness as independent variables and employee adaptability as dependent variable. Questionnaire comprising 34 questions were circulated among sample of 240 and responses were assessed using five-point Likert scale. Simple random sampling method was used to select sample which comprised bank executives in both government and private commercial banks in Sri Lanka. Generation wise multiple regression analysis and ANOVA multi group comparisons were used as major data analysis techniques. Results concluded that, the impact of big five personality traits on employee adaptability vary among generations. Study contributed existing body of knowledge by addressing area where gap exist in theory and context. Guidance for practitioners were offered exploring generation wise conceptual models while portraying practical and actionable recommendations crucial for management.
\end{abstract}

Keywords:- Big Five Personality Traits, Employee Adaptability, Multiple Generations, Banking Industry

\section{INTRODUCTION}

The banking sector is always deemed to be crucial for economic development of any country. As a key component in financial sector banks hold and invest in financial assets to leverage way to create more wealth. Moreover, banks involve in providing liquidity to whole economy while mitigating and transforming risk characteristics of assets. To name a 
few providing payment services, facilitating entities to carry out transactions, transferring funds from savers to borrowers in an efficient manner are other some key services carryout by banks.

Sound banking sector is crucial for the sustainability of financial sector irrespective of the country. In Sri Lanka as a developing country, banks play a vital role in developing infrastructure financing, initiating rural development activities from the root level so forth. In Sri Lanka sustainability of any industry depend on the quality of workforce since Sri Lankan economic system largely rely on human capital. Quality of workforce fluctuate due to various concerns. As an industry which brings out regular innovations.

Low employee adaptability deemed to be a dynamic issue face by banking industry. Now a days organizational environments are rapidly changing and employee adaptability is extremely important to upgrade organizational performance, enhance competitiveness so forth (Dam, 2009). According to Earnst and Young (2018) every bank is working towards improving operational efficiencies and customer experience and there are various technologies emerge like process automations and adaptive intelligence.

According to the complexity in present context people need to perform at least four or five careers relatedly in the bank rather than sticking into one role, which made need in adaptive employees to face these changes successfully. Evidence obtained through pilot study proved that there is an issue regarding employee adaptability since employees get transfers in regular time intervals like every five year and job rotations among lower counter, cashier, credit section, pawning section so forth is so hard. As an industry which bring out regular innovations to sustain in the market low employee adaptability would become as a key issue. Frontline employees need to adapt to differing demands to represent organization in positive manner.

Among the factors which make considerable impact on employee adaptability, researchers identified big five personality traits as an important area to discuss. Previous studies revealed that personality made an impact on job performance, customer loyalty, reduce turnover, bank profitability so forth (Rashid, Sah, Ariffin, Abdul, \& Muhamad, 2016). It led to provoke researchers' interest towards the area.

Labor force in bank consist employees belong to different generations and generational differences emerged as a dominant area discuss by researchers in present context. In every point of history, workforce comprised employees belong to different generations (McKinlay \& Vicki, 2010). According to Half (2017) managers should see building a diversified team with new perspectives as a plus point and managers need to identify multigenerational differences on various perspectives. In light to the above facts previous studies conducted by UK Essays (2018) and Ludviga \& Irina (2016) revealed that 
there are employee adaptability differences prevail among generations.

Considering above facts researchers cascaded the target group into three generations: generation $\mathrm{X}, \mathrm{Y}$ and $\mathrm{Z}$ which the bank staff constitute of to conduct study in a broader perspective. Importance of banking sector as a main arm in financial sector along with the researchers' interest in studying psychological aspects profoundly motivated researchers to conduct the study. Key objective of conducting the study was to study how the personality traits of different employee generations effect on their adaptability. Moreover, to study how the generational differences of employee adaptability is effected by their personality traits is the next objective of the study.

Selection of banking industry for the study was justified by the fact that Sri Lankan banking industry comprise about $40 \%$ of total workforce (UK Essays, 2018). Selection of Colombo surburb branches were based on the criteria that majority of banking outlets were located in Colombo accounting 960 branches according to central bank reports. Researchers selected every element of the study based on strong justificable criteria with the intention of enhancing standard of research.

However, research found a gap exist in study area in terms of theory and research context. Due to the availability of limited literature researchers tried to bridge the knowledge gap by providing practical, theoretical and contextual contribution from the research. Outcome of the study benefit different fields of interest like future researchers, policy makers and banking industry since it provides valuable insights on each key dimension. As human capital is the most important element of any organization, identifying and upgrading value of human capital is important, especially in service sector. In service sector quality of the service is assessed at the point where employee - client interacts and at that touchpoint client tend to examine the way employee talk, behave, respond to urgent matters, gestures, postures etc. Researchers conducted the study targeting a giant in service and finance industry; banking industry because banking industry is an industry where personality matters most. Since bankers must undergo frequent changes related to job tasks, working environments, technology etc. employee adaptability has become a significant area which banking industry focus most.

The findings of the study enable to identify how selected sub elements of each personality trait contribute to upgrade employee adaptability. At the same time provides the identification of generational impact of big five personality traits on employee adaptability. Furthermore, finding of the study will assist to improve employee adaptability by upgrading relevant personality traits. Implementers, policy makers in banks can use the results of the study as a reference guide when designing personality development trainings and when designing organizational 
policies. Results of the study aid other interested party by providing valuable insights useful for academic purposes and when developing prudent initiatives to overcome generational based employee adaptability issues.

\subsection{Theoretical Background}

Personality can be defined as an individual's preferred or typical way of behaving, thinking and feeling (Wong, Gardiner, Lang, \& Coulon, 2008). Employee's personality determine how they will react in certain situations and what training and managing approaches are most effective for them. Personality trait is a stable characteristic pattern of behavior, emotions and thoughts which can describe individual's behavior in each situation (Sripom, Rungswang, Sukwitthayakul, \& Chansri, 2019). There are some trend that can be found when one was born, grew up and which affects personality traits and perspectives (Durisko, 2018). One of the popular term associated with personality is "Big Five" coined by scholar Goldberg in 1976. According to him five factors consist neuroticism, extraversion, openness to experience, agreeableness and conscientiousness. Neuroticism means individual's emotional stability and tendency to have negative emotions. People with high score in neuroticism are likely to worry, angry, depressed, fear and have anxiety and people with low score are more relaxed, calm and secure (Sripom, Rungswang, Sukwitthayakul, \& Chansri, 2019). Extraversion express person's assertiveness, emotional expression and comfort levels in certain situations (Grohol, Psych Central, 2019). Conscientiousness refers to individuals who demonstrate traits of self-control by means of being capable of planning, organizing and working strategically towards achieving goals (Rodrigo \& Jayasekara, 2016). Agreeableness is a characteristic associated with being friendly, caring and corporative. People who possess high score in agreeableness tend to be get along with others while people with low score tend to be more skeptical competitive and distant. Openness to experience refers to extent to which people take risks and take an interest in new experiences. People who possess high openness have high flexibility, curiosity and imagination while people with low score tend to be conservative, traditional and practical (Sripom,Rungswang, Sukwitthayakul, \& Chansri, 2019).

Employee adaptability refers to "employee's underlying potential as derived from cognitive, affective and behavioral resources that can be applied to effectively adjust and or anticipate to task related, environmental and vocational demands" (Dam, 2009). According to career construction theory adaptability is a core psychosocial resource or transactional competency necessary for achieving adaptive goals (Yang, Feng, Meng, \& Yong, 2019).

Findings of Dam (2009), Spiro \& Weitz (1990), Whiler, Meurs, Daniela, Troll, \& Bilckle (2017), Huang, Ryan, Zable, \& Palmer (2013), Dursun, Tahir, \& Mehpare 
(2017) identified personality traits that have an impact on employee adapatability. According to Echchakoui (2013) conscientoiusness, agreeableness and emotional stability postively associated with employe adapatbility and extraversion and openness negatively affect employee adapatbility. Another study revealed self mintoring, interpersonal control and openning positively correlate with adaptive behaviour while rigitidy negatively correlate with adaptive behaviour (Verbeke, 1994). A study conducted by Griffin \& Hesketh (2005) stated that only achievement facets of conscientiousness relate to employee adapatability. Furthermore, studies conducted by Psych Tests (2015), Donnellan \& Lucas (2008), Zahari (2016), Grohol (2019), Durisko (2018) found generational differences in personality traits. When considering employee adapatbility Earnst and Young (2018) and Ludviga \& Irina (2016) found generational differences in employee adapatbility. Accordingly, research hypotheses were developed as;

$\mathrm{H}_{1}$ : Employee adoptability of generation $\mathrm{X}$ is significantly affected by their personality dimensions.

$\mathrm{H}_{2}$ : Employee adoptability of generation $\mathrm{Y}$ is significantly affected by their personality dimensions

$\mathrm{H}_{3}$ : Employee adoptability of generation $\mathrm{Z}$ is significantly affected by their personality dimensions

$\mathrm{H}_{4}$ : There are generational differences of employee adaptability and employee personality dimensions

\section{METHODS}

Researcher adopted quantitative enquiry as research approach and used structured questionnaire as research instrument to obtain data from sample. Structured questionnaire was cascaded into two sections where researcher measured demographics under first phase while measuring personality traits and employee adaptability using fivepoint Likert scale under second phase. Cronbach's alpha values for neuroticism, extraversion, openness, agreeableness, conscientiousness and employee adaptability were 0.969 , $0.968,0.973,0.965,0.975$ and 0.991 respectively indicating excellent level of reliability according to Gliem \& Gliem (2003).

Study confined the target population to all bank executives in Colombo suburb branches to derive better results from a representative sample. Due to unavailability of reliable sources unknown population was assumed and selection of sample was based on Green's recommendation (1991). Simple random sampling method was applies to select 240 bank executives in five leading banks including both government and private banks. Number of responses were 208 yielding a response rate of $86.6 \%$. Researchers conducted cross sectional analysis in natural study setting with minimum interference to yield results. Researchers used both inferential and descriptive statistics to produce the results and multiple regression, ANOVA multi group comparisons were used as main data 
analysis techniques to test hypothesis

developed under the study.

\section{RESULTS}

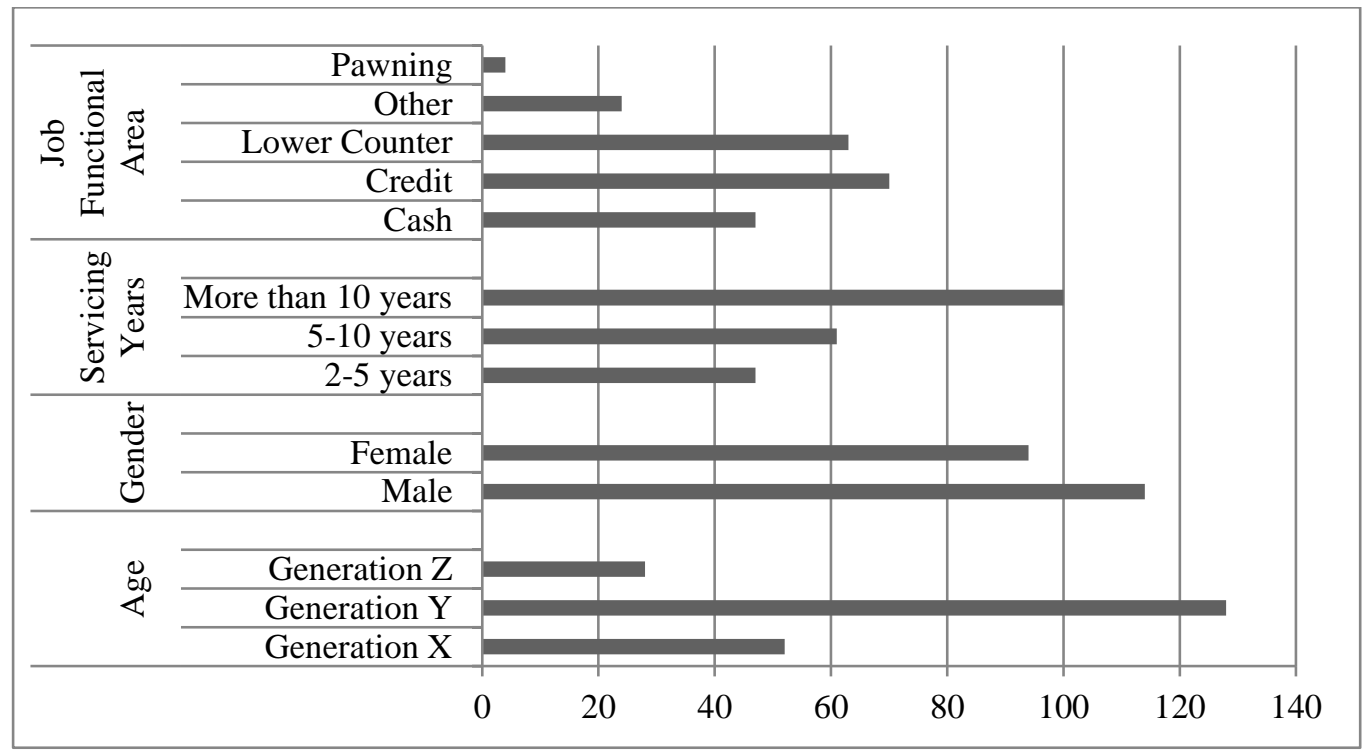

Source: Survey data, 2020

Figure 1: Demographic Data of Sample

Figure 1 exemplify demographic data of sample assessed with the aim of identifying generational and gender composition of sample along with job functional area and service period. According to the results majority of respondents were belong to generation $\mathrm{Y}$ and mainstream were male. Sample composition included $48 \%$ employees work over 10 years which steered to upgrade exactitude of research. As diagram depict job functional area diversified across several functions.

\section{Test of Hypotheses}

In order to test the developed hypotheses multiple regression analysis was performed. Initially, the study aimed at testing heteroscedasticity, multicollinearity and autocorrelation to assess whether data set is free from heteroscedasticity, multicollinearity and autocorrelation problem. Researchers checked heteroscedasticity based on Breusch Pagan test and according to the results of Breusch - Pagan test ANOVA significance values were greater than 0.05 . The results supported null hypothesis and the results concluded that data is 
homoscedastic (Breusch \& Pagan, 1979). According to the output of multicollinearity test, all five variables indicated VIF values below 10 and concluded data set is free from multicollinearity problem.

Durbin - Watson values for all five variables were in line with the rule according to Statistics solutions (2020) and concluded that there were no autocorrelation problem in data set. Further, Skewness, kurtosis values and PP plots proved normal distribution of data according to Rose, Spinks (2015) and Hair, Hult, Ringle, \& Sarstedt (2015). Pearson's Correlation table and linearity diagrams proved linearity of the sample. Results of the multiple regression were shown in the following tables

Table 1: Multiple regression analysis predicting employee adoptability of generation $\mathrm{X}$ employees' personality

\begin{tabular}{|l|l|l|l|l|l|}
\hline \multicolumn{5}{|c|}{ Model Summary } & \\
\hline Model & R & R Square & Adjusted R Square & F change & Sig \\
\hline 1 & .93 & .87 & .86 & 64.90 & .00 \\
\hline
\end{tabular}

Source: Survey data, 2020

Table 2: Statistical output of the multiple regression analysis

\begin{tabular}{|c|c|c|c|c|c|}
\hline & & Coefficien & & & \\
\hline \multirow[t]{3}{*}{ Model } & \multirow{2}{*}{\multicolumn{2}{|c|}{$\begin{array}{l}\text { Unstandardized } \\
\text { Coefficients }\end{array}$}} & \multirow{3}{*}{\begin{tabular}{|l|}
$\begin{array}{l}\text { Standardized } \\
\text { Coefficients }\end{array}$ \\
Beta
\end{tabular}} & \multirow[t]{3}{*}{$\mathrm{T}$} & \multirow[t]{3}{*}{ Sig. } \\
\hline & & & & & \\
\hline & $\mathrm{B}$ & Std. Error & & & \\
\hline \multirow{2}{*}{$\begin{array}{l}\text { (Constant) } \\
\text { Neuroticism }\end{array}$} & .43 & .19 & & 2.21 & .03 \\
\hline & .64 & 1.0 & 1.75 & 1.52 & .13 \\
\hline Extraversion & .86 & .60 & .91 & 1.41 & .16 \\
\hline \multirow{2}{*}{$\begin{array}{l}\text { Openness } \\
\text { Agreeableness }\end{array}$} & .41 & 1.9 & -6.11 & -2.90 & .00 \\
\hline & .20 & .62 & .22 & .33 & .74 \\
\hline Conscientiousness & .25 & 1.07 & 4.14 & 3.59 & .00 \\
\hline
\end{tabular}

Source: Survey data, 2020

According to the table 1 , adjusted $\mathrm{R}$ square of the model is 0.86 . That means employee personality dimensions in the model explain $86 \%$ of the total variance in the dependent variable of employee adoptability. Table 2 shows the regression coefficients of the independent variables with their significance. It shows that of Neuroticism, Extraversion and Agreeableness have become insignificant. Openness dimension has the strongest Beta value at 0.41 implying that there is a positive impact with the employee adoptability. Next, 
consciousness dimension has a Beta value of 0.25 implying that there is a positive impact on employee adoptability. In relation to hypothesis 1 , that argue employee adoptability of generation $\mathrm{X}$ is significantly affected by their personality dimensions, it was revealed that both openness and conscientiousness have a positive influence on employee adaptability of generation $\mathrm{X}$.

Table 3: Multiple regression analysis predicting employee adoptability of generation $Y$ employees' personality

Source: Survey data, 2020

\begin{tabular}{|c|c|c|c|c|c|c|}
\hline \multicolumn{5}{|c|}{ Model Summary } & \multirow[b]{2}{*}{$\mathrm{df}$} & \multirow[b]{2}{*}{ Sig } \\
\hline Model & $\mathrm{R}$ & R Square & $\begin{array}{l}\text { Adjusted } \\
\text { Square }\end{array}$ & $\mathrm{R} F$ change & & \\
\hline 1 & .97 & .95 & .95 & 533.8 & 5 & .00 \\
\hline
\end{tabular}

Source: Survey data, 2020

Table 4: Statistical output of the multiple regression analysis

\begin{tabular}{|c|c|c|c|c|c|}
\hline \multirow[t]{2}{*}{ Model } & \multicolumn{2}{|c|}{$\begin{array}{l}\text { Unstandardized } \\
\text { Coefficients }\end{array}$} & \multirow{2}{*}{$\begin{array}{l}\text { Standardized } \\
\text { Coefficients } \\
\text { Beta }\end{array}$} & \multirow[t]{2}{*}{$\mathrm{T}$} & \multirow[t]{2}{*}{ Sig. } \\
\hline & B & Std. Error & & & \\
\hline (Constant) & .26 & .09 & & 2.84 & .00 \\
\hline Neuroticism & .38 & .10 & .39 & 3.80 & .00 \\
\hline Extraversion & .20 & .07 & .20 & 2.83 & .00 \\
\hline Openness & .09 & .03 & .12 & 2.60 & .01 \\
\hline Agreeableness & -.29 & .13 & -.30 & -2.13 & .03 \\
\hline Conscientiousness & .54 & .11 & .58 & 4.90 & .00 \\
\hline
\end{tabular}

Source: Survey data, 2020

According to the table 3, adjusted $\mathrm{R}$ square of the model is 0.95 . That means employee personality dimensions in the model explain 95\% of the total variance in the dependent variable of employee adoptability. Table 4 shows the regression coefficients of the independent variables with their significance. It revealed that of all the personality dimensions have become significant. Conscientiousness dimension has the strongest Beta value at 0.54 implying that there is a strong positive impact on the employee adoptability. Secondly, Neuroticism dimension has 
a Beta value of 0.38 implying that there is a positive impact on employee adoptability. Thirdly, agreeableness dimension has a beta value of -0.29 implying that there is a negative impact on employee adoptability. Next, extraversion dimension has a Beta value of 0.20 implying that there is a positive impact on employee adoptability. Then openness dimension has the lowest Beta value of 0.09 implying that there is a lower positive impact on employee adoptability.
In relation to hypothesis 2 , that argue employee adoptability of generation $\mathrm{Y}$ is significantly affected by their personality dimensions, it was revealed that Neuroticism, Extraversion, Openness and Conscientiousness have a positive influence on employee adaptability while Agreeableness has a negative influence on employee adaptability of Y generation.

Table 5: Multiple regression analysis predicting employee adoptability of generation $\mathrm{Z}$ employees' personality

\begin{tabular}{|l|l|l|l|l|l|l|}
\hline \multicolumn{5}{|c|}{ Model Summary } & & \\
\hline Model & R & R Sq. & Adjusted R Square & F change & df & Sig \\
\hline 1 & .98 & .97 & .96 & 172.49 & 5 & .00 \\
\hline
\end{tabular}

Source: Survey data, 2020

Table 6: Statistical output of the multiple regression analysis

\begin{tabular}{|c|c|c|c|c|c|}
\hline \multirow[t]{2}{*}{ Model } & \multicolumn{2}{|c|}{$\begin{array}{l}\text { Unstandardized } \\
\text { Coefficients }\end{array}$} & $\begin{array}{l}\text { Standardized } \\
\text { Coefficients }\end{array}$ & \multirow[t]{2}{*}{$\mathrm{T}$} & \multirow[t]{2}{*}{ Sig } \\
\hline & B & Std. Error & Beta & & \\
\hline (Constant) & 1.49 & .53 & & 2.79 & .01 \\
\hline Neuroticism & .74 & .14 & .75 & 5.24 & .00 \\
\hline Extraversion & -.01 & .06 & -.01 & -.30 & .76 \\
\hline Openness & .76 & .16 & .89 & 4.77 & .00 \\
\hline Agreeableness & -.52 & .19 & -.62 & -2.68 & .01 \\
\hline Conscientiousness & -.26 & .11 & -.11 & -2.31 & .03 \\
\hline
\end{tabular}

Source: Survey data, 2020

According to the table 5, adjusted $\mathrm{R}$ square of the model is 0.96 . That means employee personality dimensions in the model explain $96 \%$ of the total variance in the dependent variable of employee adoptability. Table 6 shows the regression coefficients of the independent variables with their significance. It revealed that of all 
the personality dimensions except Extraversion have become significant. Openness dimension has the strongest Beta value at 0.76 implying that there is a strong positive impact on the employee adoptability. Neuroticism dimension has a Beta value of 0.74 implying that there is a strong positive impact on employee adoptability.

Agreeableness and Conscientiousness dimensions have a beta value of -0.528 and -0.268 implying that there is a negative impacts on employee adoptability.

In relation to hypothesis 3 , that argue employee adoptability of generation
$\mathrm{Z}$ is significantly affected by their personality dimensions, it was revealed that Neuroticism and Openness have a positive influence on employee adaptability while Conscientiousness and Agreeableness have a negative influence on employee adaptability of $\mathrm{Z}$ generation. Further, Extraversion dimension is no longer a valid dimension in predicting the employee adoptability of generation Z.ANOVA multiple comparisons were used to assess whether there is a difference in personality dimensions and employee adaptability among generation $\mathrm{X}, \mathrm{Y}$ and $\mathrm{Z}$.

Table 7: ANOVA Multiple Comparison - Employee Adaptability

\begin{tabular}{|c|c|c|c|c|c|c|c|}
\hline \multicolumn{8}{|c|}{ Multiple Comparisons } \\
\hline \multicolumn{8}{|c|}{ Dependent Variable: Employee Adaptability } \\
\hline \multicolumn{8}{|c|}{ Tukey HSD } \\
\hline \multirow[t]{2}{*}{ (I) Age } & \multirow[t]{2}{*}{ (J) Age } & \multirow{2}{*}{$\begin{array}{l}\text { Mean } \\
(\mathrm{I}-\mathrm{J})\end{array}$} & \multirow{2}{*}{ Difference } & \multirow{2}{*}{ Std. Error } & \multirow[t]{2}{*}{ Sig. } & \multicolumn{2}{|c|}{$95 \%$ Confidence Interval } \\
\hline & & & & & & Lower Bound & Upper Bound \\
\hline \multirow[t]{2}{*}{ Gen. X } & Gen. Y & -.95 & & .09 & .00 & -1.19 & -.72 \\
\hline & Gen. Z & -1.15 & & .14 & .00 & -1.48 & -.82 \\
\hline Gen. Y & Gen. Z & -.19 & & .12 & .25 & -.49 & .09 \\
\hline
\end{tabular}

Source: Survey data, 2020

According to table 7 there was a mean difference in employee adaptability among generation $X$ and $\mathrm{Y}, \mathrm{X}$ and $\mathrm{Z}$ since significance values were .000 which was less than 0.05 and there was no mean difference in employee adaptability among generation $\mathrm{Y}$ and $\mathrm{Z}$ since significance value was .259 at significant level 0.05 .

In relation to hypothesis 4 that argue there are some generational differences of employee adaptability and employee personality dimensions is accepted based on the above statistical finding. 


\section{DISCUSSION}

Employee adaptability issues are rising in Sri Lankan banking context. Impact of big five personality traits on employee adaptability targeting multiple generations were not being subjected to significant empirical research previously. Results of the quantitative study revealed that impact of big five personality traits on employee adaptability vary among generations in terms of direction and magnitude of impact while some variables remain non -impacting.

When considering the results of the study researchers found that openness positively impact on employee adaptability of generation $\mathrm{Y}$ and $\mathrm{Z}$ and it was compatible with the findings of Dam (2009), Spiro \& Weitz (1990), Verbeke (1994). However, openness showed negative impact on employee adaptability of generation $\mathrm{X}$ and it was compatible with the findings of Echchakoui (2013). Extraversion showed an impact on employee adaptability generation $\mathrm{Y}$ and it was compatible with the findings of Wihler, Meurs, Wiesmann, Troll, \& Blickle (2017). Conscientiousness showed positive impact on employee adaptability of generation $\mathrm{X}$ and $\mathrm{Y}$ and negative impact on employee adaptability of generation Z. However, according to Griffin \& Hesketh (2005) only achievement facets of personality associate with employee adaptability.

As practical contribution findings of the study derived actionable and prudent implications for the bank management while providing theoretical contribution for future researchers by deriving three separate models for generation $\mathrm{X}, \mathrm{Y}$ and $\mathrm{Z}$.

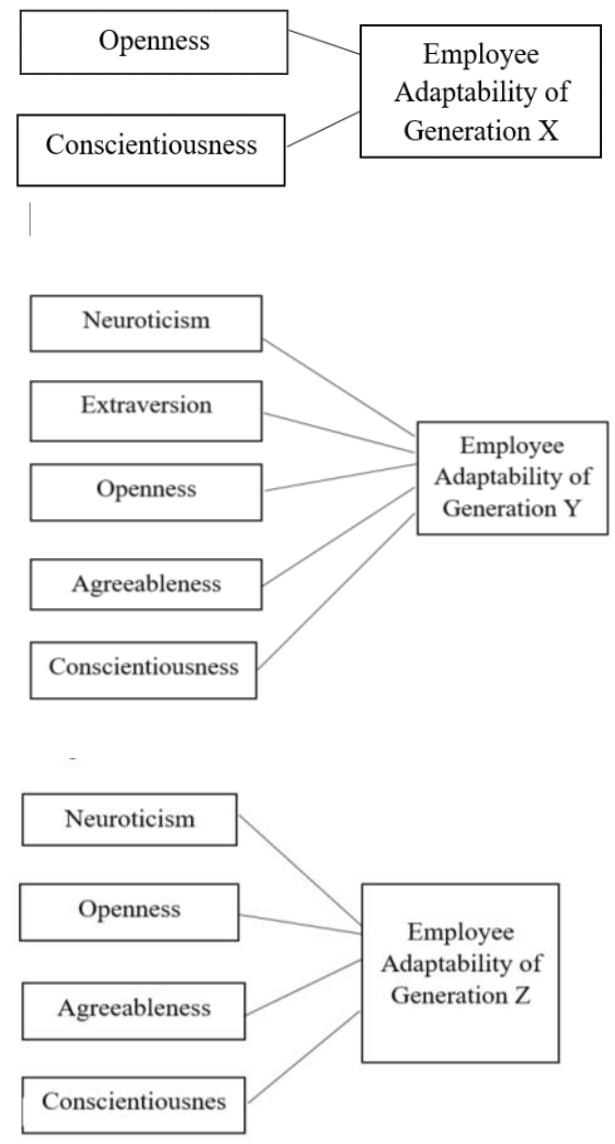

Figure 1: Conceptual framework

As per the results of multiple regression analysis, neuroticism did not make an impact on employee adaptability of generation $\mathrm{X}$, but it made a positive impact on employee adaptability of generation $\mathrm{Y}$ and $\mathrm{Z}$. Moreover, neuroticism made high impact on employee adaptability of generation $\mathrm{Z}$ than generation $\mathrm{Y}$. Under neuroticism researchers measured ability to deal with stress, level of self-consciousness, level of stability in personality and level of job security since these dimensions 
lead to reduce neurotic nature of people. Since neuroticism made positive impact on employee adaptability of generation $\mathrm{Y}$ and $\mathrm{Z}$, development of a proper mechanism is needed to enhance it. Since bankers are engaging in highly stressful financial activities by nature there is need to develop employee's ability to cope up with stress. In that manner it is suggested to provide employees paid compulsory leave and social support while not giving excessive workloads and unclear performance expectations. Moreover, enhancing self-consciousness of employees by pushing towards a system where each employee can learn to be responsible while accepting open criticism is needed. As well as enhancing job security by cultivating a secure atmosphere and by linking employees with future goals and orientations of the bank, the desired outcome can be achieved.

When considering multiple regression results of extraversion, it showed a positive impact on employee adaptability of generation $\mathrm{Y}$ and it did not show an impact on employee adaptability of generation $\mathrm{X}$ and $\mathrm{Z}$. Under extraversion researchers measured level of friendliness, level of self-confidence, level of social confidence and ability to articulate as key indicators. To improve level of friendliness it is necessary to encourage employees to adhere to team-oriented approaches by arranging staff get together, trips etc. To develop self-confidence of employee's need arises to treat them with respect while encouraging employees to learn through mistakes. Proper mentoring program can yield good results. Providing a proper training and a timely feedback, developing open communication, celebrating employee's improvements would yield good results by developing social confidence.

When considering openness, it showed openness have negative impact on employee adaptability of generation $\mathrm{X}$ while it makes positive impact on employee adaptability of generation $\mathrm{Y}$ and $\mathrm{Z}$. Under openness researchers tested preference for new ideas and changes, level of creativity, insightfulness and openness to various values and beliefs as key aspects. Under the trait openness since generation $\mathrm{X}$ resulted a different outcome when compared to generation $\mathrm{Y}$ and $\mathrm{Z}$ there is need to get thorough understanding about generation $X$ 's perspective about openness. In detailed analysis should target generation $\mathrm{X}$ to assess whether these key differences are inherent to generation or whether there are some other reasons that influenced their perspective. Regarding generation $\mathrm{Y}$ and Z, making employees' awareness about changes while encouraging them to be a part of change management process would make feel important and notable while eliminating conflicts regarding changes. Each action in change management process should be followed by a strong justification to make employees feel that changes are crucial for organizational success. Train employees to adhere to a culture where each employee will treat with equal respect and dignity irrespective of religion, age, gender etc. is needed. Proper cultural 
orientation should be developed within the organization to enhance employee adaptability.

Trait agreeableness showed negative impact on employee adaptability of generation $\mathrm{Y}$ and $\mathrm{Z}$. However, agreeableness did not make an impact on employee adaptability of generation $\mathrm{X}$. Under agreeableness researchers used level of politeness, cheerfulness, consideration and level of helpfulness as indicators. There is need to conduct an in-depth analysis to identify the reasons behind the answers. Management should assess employee's perspectives to facilitate them with necessary guidelines and actions.

When considering conscientiousness, it spelled out positive impact on employee adaptability of generation $\mathrm{X}$ and $\mathrm{Y}$. According to beta coefficients it showed conscientiousness have high impact on employee adaptability of generation $\mathrm{X}$ than $\mathrm{Y}$. Conscientiousness showed negative impact on employee adaptability of generation $Z$. Under conscientiousness researchers measured self-discipline, level of reliability, capability of working strategically and hardworking ability. For the executives belong to generation $\mathrm{X}$ and $\mathrm{Y}$, there is need to develop rules to enhance selfdiscipline and teach and appraise good behavior. These rules should be aimed at developing employee morale to encourage and to behave ethically with good discipline in the workplace. To enhance reliability of work, clear and realistic policies and tasks need to be developed while offering flexible and enjoyable working environment. To improve employee capabilities while encouraging them to work hard utilization of right technologies and strategies are needed. Furthermore, empowering employees with decision making power while clearly communicating expectations is essential. Appraisal mechanism directed towards career success or financial rewards can improve hardworking ability of employees and then adaptability.

\section{CONCLUSION}

Researchers attempted to bridge the knowledge gap by conducting the study since there were only few researches done on the area discussed. Researchers made a contextual contribution by grounding the study on banking sector. Bank management should focus on each aspect in depth along with the recommendations provided by the researchers to mitigate issues prevail in the organization in terms of subject area discussed to bring more value to the table.

It is reasonable to state that every research has limitations irrespective of the area of study. It might be because researchers could not possibly bring the whole perspective of an area in one fine study. Hence, like other researches the present research endeavor also suffers from some limitations. If discuss limitations researchers used quantitative method in the study to assess the impact of big five personality traits on employee adaptability. However, personality traits are a subjective topic, it is more 
appropriate to use mixed method for study to obtain detailed information about the aspects researchers wish to investigate further. Also, study suggests to use more cross verification-based questions to reject answers which does not match with previous answers. Furthermore, future researchers can target other industries, other provinces and other employee categories that may suffer with employee adaptability issues. Moreover, future researchers can conduct this study as a longitudinal study rather than conducting a cross sectional study to provide respondents more time to respond and to motivate them to give more accurate answers while yielding high response rate.

\section{REFERENCES}

Breusch, T., \& Pagan, A. (1979). A simple test for heteroskedasticity and random coefficient variation. Econometrica.

Dam, K. V. (2009). Employee adaptability to change at work: A multidimensional, resourcebased framework. 123 - 142.

Donnellan, B., \& Lucas, R. E. (2008). Age Differences in the Big Five Across the Life Span: Evidence from Two National Samples. Psychol Aging Author Manuscripts, 23(3), $558-566$.

Durisko, J. (2018). Ving. Retrieved January 4, 2019, from https://blog.vingapp.com.howpersonality-differences- between-generations-changetraining.

Dursun, M., Tahir, A., \& Mehpare, T. (2017). Does Personality Affect Career Adaptability. International Journal of Humanities Social Sciences and Education (IJHSSE), 4(10), 107 - 115.

Earnst and Young. (2018). EY.Com. Retrieved August 7, 2020, from

https://www.ey.com/Publicatio n/vwLUAssets/ey-the-futureof-talent-in-banking/\$File/eythe-future-of-talent-inbanking.pdf.

Echchakoui, S. (2013). Personality traits and performance: The meadiating role of adapative behavior in call centers. American Journal of Industrial and Business Management, 3(1), $1-11$.

Gliem, J., \& Gliem, R. (2003 ). Calculating, interpreting and reporting Cronbach's Alpha reliability coefficient for likert type scales. 2003 Midwest Research to Practice Conference in Adult, Continuing and Community Education, 82 - 88.

Green, S. B. (1991). How many subjects does it take to do a regression analysis? Multivariate Behavioral Research, 26, 499-510.

Griffin, B., \& Hesketh, B. (2005). Are Conscientious Workers Adaptable. Australian Journal 
of Management, 30(2), 245 259.

Grohol, J. M. (2019, November 21). Psych Central. Retrieved August 8, 2020, from https://psychcentral.com./lib/th e-big-five-personality-traits/

Hair, J., Hult, G., Ringle, C., \& Sarstedt, M. (2017). A primer on partial least sqaure structural equation modeling.

Half, R. (2017). Robert Half Business. Retrieved August 7, 2020, from https://www.roberthalf.com/blo g/management-tips/the-key-tomanaging-a-multigenerationalteam-dont-overthink-it.

Huang, J., Ryan, A. M., Zable, K., \& Palmer, A. (2013). Personality and Adaptive Performance at Work: A Meta Analytic Investigation. Journal of applied pschology, 99(1), 162 179.

Ludviga, I., \& Irina, S. (2016). Organizational change: generational differences in reaction and commitment. 9 th International Scientific Conference (pp. 1- 11). Vilnius: VGTU Press.

McKinlay, J., \& Vicki, W. (2010). Generational Differences. The art of people management in libraries(2).

Psych Tests. (2015, August 29). Cision PRWeb. Retrieved August 8, 2020, from https://www.prweb.com/releas es/2015/08/prweb12927072.ht

$\mathrm{m}$.

Rashid, N., Sah, N., Ariffin, N., Abdul, G. W., \& Muhamad, Y. N. (2016). The influence of bank's frontline traits on job performance. Periodica economics and financial journal, 65 - 72 .

Rodrigo, B., \& Jayasekara, P. (2016). The impact of Personality on Job Performance: Study on Senior Managers in State Owned Commercial Banks in Colombo District, Sri Lanka. Human Resource Management Journal, 4(2), 23.

Rose, S., Spinks, N., \& Isabel, A. (2015). Management Research: Applying the principles. 1-4.

Spiro, R., \& Weitz, B. (1990). Adaptive Selling: Conceptualization, Measurement and Nomological Validity. Journal of Marketing Research, 27(1), 61 - 69.

Sripom, C., Rungswang, A., Sukwitthayakul, C., \& Chansri, N. (2019). Personality Traits of Thai Gen Z Undergraduates:Challeges in EFL Classroom. PASSA, 57, 1 $-26$.

Statistic Solutions. (2020). Retrieved August 8, 2020, from https://www.statisticssolutions. com/heteroscedasticity.

UK Essays. (2018). Retrieved August 7, 2020, from https;/www.ukessays.com/essa ys/business/inside-the-banking- 
industry-in-sri-lamka-businessessay.php?vref=1

Verbeke, W. (1994). Personality Characteristics That Predict Effective Performance of Sales People. 10(1), 49 - 57.

Whiler, A., Meurs, J., Daniela, W., Troll, L., \& Bilckle, G. (2017). Extraversion and adapative performance: Intergrating trait activation and socionalytic theories at work. Extraversion and adapative performance: Intergrating trait activation and socionalytic theories at work, 116, $133-138$.

Wong, M., Gardiner, E., Lang, W., \& Coulon, L. (2008, November). Generational differences in personality and motivation Do they exist and what are the implications for workplace? Journal of Managerial Psychology, 23(No 8), 880.

Yang, X., Feng, Y., Meng, Y., \& Yong, Q. (2019, May). Career Adaptability, Work Engagement, and Employee Well-Being Among Chinese Employees: The Role of Guanxi. Frontiers in Psychology, 10.

Zahari, N. A. (2016). Personality traits and differences of generations: do they affect public servants job performance. Journal of Global Business and Social Entrepreneurship (GBSE), 2(4), 20 - 30. 